\title{
Inhibition of Klenow DNA polymerase and poly(A)-specific ribonuclease by aminoglycosides
}

\author{
YAN-GUO REN, ${ }^{1}$ JAVIER MARTÍNEZ,, ${ }^{1,2}$ LEIF A. KIRSEBOM, ${ }^{1}$ and ANDERS VIRTANEN ${ }^{1}$ \\ ${ }^{1}$ Department of Cell and Molecular Biology, Uppsala University, SE-751 24 Uppsala, Sweden
}

\begin{abstract}
Aminoglycosides are known to bind and perturb the function of catalytic RNA. Here we show that they also are potent inhibitors of protein-based catalysis using Escherichia coli Klenow polymerase (pol) and mammalian poly(A)-specific ribonuclease (PARN) as model enzymes. The inhibition was $\mathrm{pH}$ dependent and released in a competitive manner by $\mathrm{Mg}^{2+}$. Kinetic analysis showed that neomycin B behaved as a mixed noncompetitive inhibitor. Iron-mediated hydroxyl radical cleavage was used to show that neomycin B interfered with metal-ion binding in the active sites of both enzymes. Our analysis suggests a mechanism of inhibition where the aminoglycoside binds in the active site of the enzyme and thereby displaces catalytically important divalent metal ions. The potential causes of aminoglycoside toxicity and the usage of aminoglycosides to probe, characterize, and perturb metalloenzymes are discussed.
\end{abstract}

Keywords: antibiotics; DNA polymerase; metalloenzymes; mRNA deadenylation

\section{INTRODUCTION}

Aminoglycosides are potent naturally occurring bactericidal antibiotics, and, as such, they have been widely used in clinical practice (reviewed in Davies, 1994; Davies \& Wright, 1997; Zembower et al., 1998). Aminoglycosides are known to perturb protein synthesis (Moazed \& Noller, 1987; Woodcock et al., 1991) by binding the A-site of the ribosome (Fourmy et al., 1996, 1998; Yoshizawa et al., 1998; Brodersen et al., 2000; Carter et al., 2000). Besides, the ribosome aminoglycosides also bind and inhibit various ribozymes (see, e.g., von Ahsen et al., 1991, 1992; Stage et al., 1995; Rogers et al., 1996; Mikkelsen et al., 1999). Several studies have revealed that aminoglycosides frequently interact with asymmetric internal loops of the RNA (Fourmy et al., 1996; Hermann \& Westhof, 1998; Yoshizawa et al., 1998; Vicens \& Westhof, 2001) and as a general model, it has been proposed that aminoglycosides bind RNA in negatively charged binding pockets (Hermann \& Westhof, 1998). It is believed that aminoglycoside binding interferes with RNA function by distorting the structure and/or by displacing functionally important divalent metal ions (Rogers et al.,

Reprint requests to: Anders Virtanen, Department of Cell and Molecular Biology, Uppsala University, Box 596, SE-751 24 Uppsala, Sweden; e-mail: anders.virtanen@icm.uu.se.

${ }^{2}$ Present address: Department of Cellular Biochemistry, Max Planck Institute for Biophysical Chemistry, Am Fassberg 11, D-37077 Göttingen, Germany.
1996; Hermann \& Westhof, 1998; Hoch et al., 1998; Mikkelsen et al., 1999, 2001; Walter et al., 1999, 2002). Displacement of divalent metal ions complexed with RNA by aminoglycosides has recently been established by structural evidence demonstrating that a neomycin B-binding site on yeast tRNA ${ }^{\text {Phe }}$ overlaps with a known divalent metal-ion binding site (Mikkelsen et al., 2001).

Divalent metal ions are frequently used by nucleic acid metabolizing enzymes to catalyze phosphodiester bond breakage or formation (reviewed by Steitz \& Steitz, 1993; Joyce \& Steitz, 1995). The crystal structures of some of these enzymes have been determined and several active sites have been defined both structurally and functionally. In general, these sites are characterized by the presence of carboxylates as exemplified in Escherichia coli DNA polymerase I (DNA pol I), where two aspartates are involved in coordinating two catalytically important divalent metal ions in the active site of polymerization. The structure of the $3^{\prime}$ exonuclease domain of $E$. coli DNA pol I has the same general organization, and here three aspartates and one glutamate coordinate the catalytically important divalent metal ions. This site is the paradigm for nucleases belonging to the RNase D family of nucleases (Mian, 1997) of which poly (A)-specific ribonuclease (PARN) is a member (Korner et al., 1998). PARN is a recently discovered eukaryotic poly(A)-specific $3^{\prime}$ exonuclease that efficiently degrades mRNA poly (A) tails (Åström et al., 1991, 1992; Korner \& Wahle, 1997; Korner et al., 1998; 


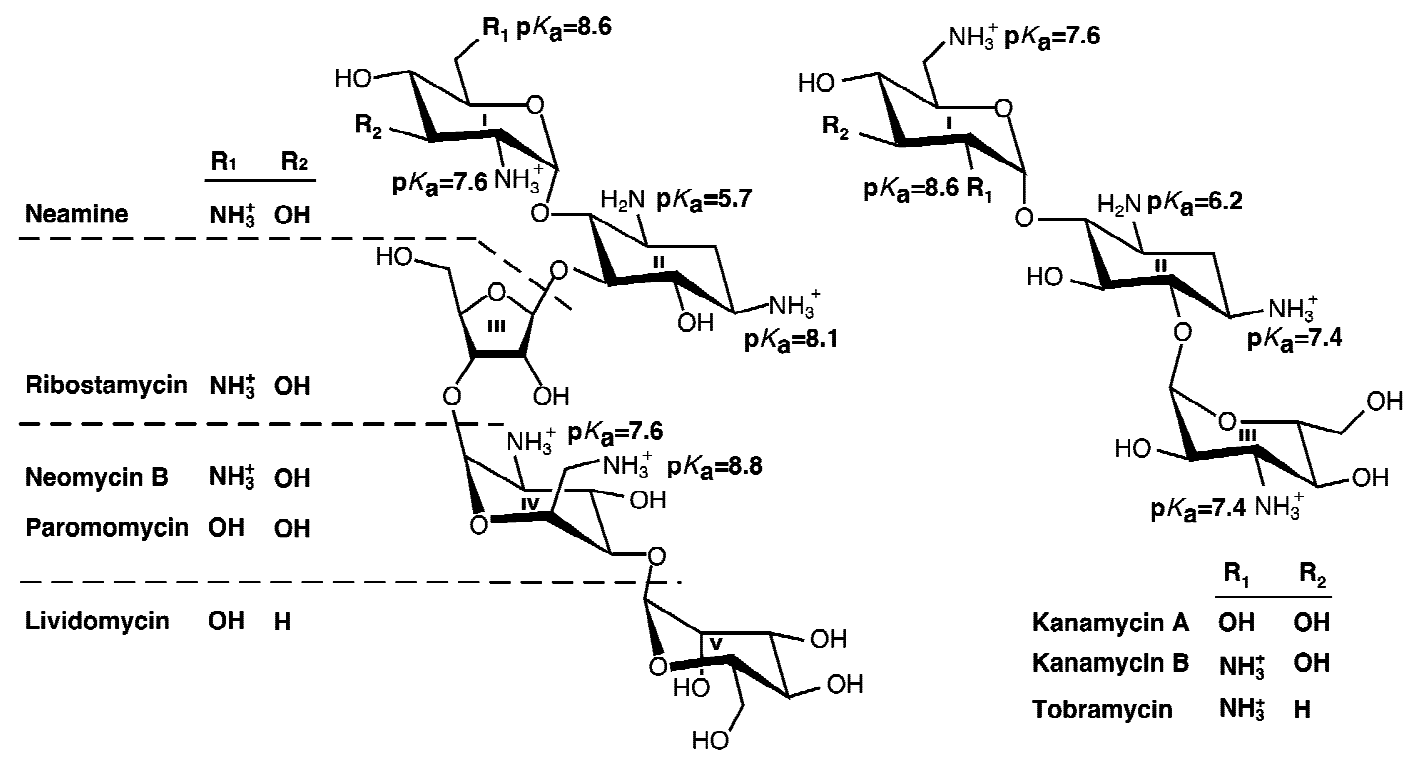

FIGURE 1. Structures of aminoglycosides belonging to the neomycin $B$ and kanamycin $B$ families are shown. Positions where the aminoglycosides differ are indicated with $\mathrm{R}_{1}$ and $\mathrm{R}_{2}$. The $\mathrm{p} K_{a}$ values for the different ammonium groups are given in the figure.

Martinez et al., 2000; Copeland \& Wormington, 2001) and its active site resembles the $3^{\prime}$ exonuclease active site of E. coli DNA pol I (Ren et al., 2002).

Hermann and Westhof (1998) noted that several active sites of nucleic acid metabolizing enzymes resemble the negatively charged binding pockets critical for aminoglycoside binding to RNA. Furthermore, they suggested that the similar arrangements of divalent metal ions in these pockets would form possible electrostatic complementary binding sites for polycationic aminoglycosides. Accordingly, they proposed that aminoglycosides should have the capacity to bind and inhibit such enzymes as well as they bind and inhibit ribozymes (Hermann \& Westhof, 1998). We have addressed this issue and investigated if aminoglycosides inhibit the enzymatic activities of $E$. coli Klenow DNA pol and mammalian PARN.

Here we demonstrate that both Klenow pol and PARN activities can be inhibited by several aminoglycosides. We propose that inhibition is caused by displacement of catalytically important divalent metal ions in analogy with inhibition of ribozyme activity by aminoglycosides. We suggest that aminoglycosides are potent inhibitors of enzymes depending on metal ions for their catalytic activity, and, as such, they can be used to probe metalion binding sites on enzymes.

\section{RESULTS}

\section{Inhibition of Klenow pol and PARN activities by aminoglycosides}

Several aminoglycosides (Fig. 1) known to inhibit a variety of ribozymes (see, e.g., von Ahsen et al., 1991,
1992; Stage et al., 1995; Rogers et al., 1996; Mikkelsen et al., 1999) were tested for their ability to inhibit Klenow pol polymerization and PARN exonuclease activities. For the studies of Klenow pol, we used a variant polypeptide in which the $3^{\prime}$ exonuclease active site was inactivated to avoid any interference from this activity (see Materials and Methods). Figure 2A shows typical inhibition curves of Klenow pol and PARN, using neomycin $B$ as the inhibitor. The apparent inhibition constants $\left({ }_{\text {app }} K_{i}\right)$ were determined to be in the low millimolar range in the case of Klenow pol and in the high nanomolar range for PARN (Table 1). The app $K_{i}$ was defined as the concentration of aminoglycoside resulting in $50 \%$ inhibition of the enzymatic activity. Similar inhibition
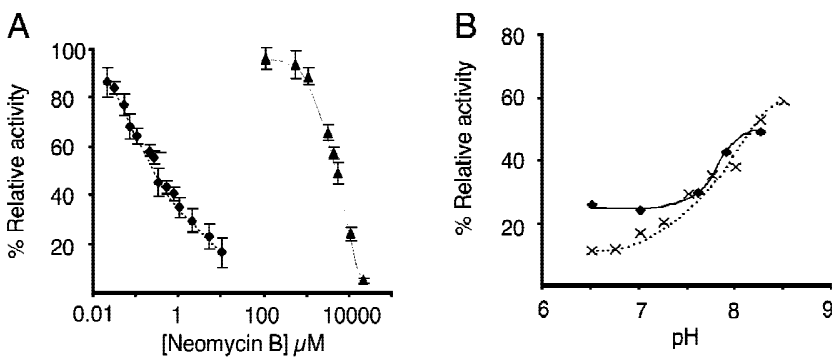

FIGURE 2. Inhibition of Klenow pol and PARN activities by the addition of neomycin B. A: Relative activity in percent is plotted as a function of increasing concentrations of neomycin B. Reactions in the presence of Klenow pol $(\boldsymbol{\Delta})$ or PARN $(\downarrow)$ were performed as outlined in the text and Materials and Methods. The average activities \pm experimental errors are shown for each concentration of neomycin B. B: Increasing the $\mathrm{pH}$ releases inhibition of Klenow pol and PARN activities by neomycin B. Relative activities for Klenow pol ( $\bullet$ and PARN $(\times)$ in percent are plotted as a function of $\mathrm{pH}$. The neomycin B concentrations were $1 \mathrm{mM}(\bullet)$ or $10 \mu \mathrm{M}(\times)$. The data points are averages of at least three independent experiments. 
TABLE 1. Inhibition of PARN and Klenow pol by aminoglycosides ${ }^{a}$

\begin{tabular}{lrr}
\hline Aminoglycoside & \multicolumn{1}{c}{$\begin{array}{c}\text { PARN } \\
\text { app } K_{i}(\mu \mathrm{M})\end{array}$} & $\begin{array}{c}\text { Klenow pol I } \\
\text { app } K_{i}(\mathrm{mM})\end{array}$ \\
\hline Neomycin B & $0.4 \pm 0.1$ & $4.8 \pm 0.3$ \\
Paromomycin & $17.3 \pm 3.5$ & $10.3 \pm 0.8$ \\
Lividomycin & $18.7 \pm 2.8$ & $11.6 \pm 2.0$ \\
Kanamycin B & $7.3 \pm 0.4$ & $9.2 \pm 0.3$ \\
Kanamycin A & $64.7 \pm 7.8$ & $14.3 \pm 1.7$ \\
Tobramycin & $7.1 \pm 0.2$ & $9.3 \pm 0.7$ \\
\hline
\end{tabular}

${ }^{\text {a }}$ The listed ${ }_{a p p} K_{i}$ values were determined as described in Materials and Methods. The given values are average \pm experimental error of several independent experiments.

curves were generated for five additional aminoglycosides and the ${ }_{\text {app }} K_{i}$ values are listed in Table 1. Our data shows that aminoglycosides inhibit both Klenow pol polymerization and PARN exonuclease activities and reveal the importance of the number of amino groups, most obviously by comparing neomycin B with paromomycin and lividomycin or kanamycin A with kanamycin B and tobramycin (Fig. 1; Table 1). In comparison with the aminoglycoside $K_{i}$ values for ribozymes, the ${ }_{\text {app }} K_{i}$ value for PARN is in the same range, whereas the ${ }_{a p p} K_{i}$ value for Klenow pol is significantly higher, approximately one order of magnitude higher than the $K_{i}$ values for the hairpin ribozyme and eukaryotic RNase $P$ (Tables 1 and 2), although it is in the same range as has previously been reported for inhibition of $E$. coli DNase I and DNA pol I (Tables 1 and 2).

\section{Inhibition requires electrostatic interactions}

It has been established that electrostatic interactions are important for inhibition of RNA function by aminoglycosides (von Ahsen et al., 1991, 1992; Zapp et al., 1993; Stage et al., 1995; Werstuck et al., 1996; Wang \& Tor, 1997; Tor et al., 1998). To investigate if electrostatic interactions were important for the inhibition of Klenow pol and PARN, we investigated the $\mathrm{pH}$ dependence for inhibition because the $\mathrm{p} K_{a}$ values of the ammonium groups (Botto \& Coxon, 1983; Szilagyi et al., 1993; Fig. 1) indicate that they are deprotonated at $\mathrm{pH}$ values above 7 . Figure $2 \mathrm{~B}$ shows that an increase in $\mathrm{pH}$ released the neomycin $\mathrm{B}$ inhibitory potential on both enzymes. Similar $\mathrm{pH}$ dependence was observed for paromomycin, kanamycin B, and kanamycin A (data not shown). Thus, our data suggests that electrostatic interactions are important for inhibition and that at least some of the ammonium groups have to be protonated.

\section{Neomycin B is a mixed noncompetitive inhibitor}

To investigate the mechanism of inhibition more carefully, we performed several sets of kinetic analyses. For Klenow pol we titrated the amount of DNA template or the dCTP nucleotide substrate at various concentrations of neomycin $\mathrm{B}$, and, in the case of PARN, we titrated the polyadenylated RNA substrate at various concentrations of neomycin $\mathrm{B}$. The results were plotted

TABLE 2. Inhibition effects of neomycin B

\begin{tabular}{lcl}
\hline Inhibited system & $\begin{array}{c}\text { Neomycin B } \\
(\mu \mathrm{M})\end{array}$ & \multicolumn{1}{c}{ Reference } \\
\hline Ribozymes $^{\mathrm{a}}$ & & \\
$\quad$ Group I intron & 0.5 & von Ahsen et al. (1991) \\
Sun Y splicing & 1.3 & von Ahsen et al. (1992) \\
Hammerhead & 13.5 & Stage et al. (1995) \\
HDV self-cleavage RNA & 28 & Rogers et al. (1996) \\
Hairpin ribozyme & 190 & Earnshaw and Gait (1998) \\
RNase P (M1) RNA & 35 & Mikkelsen et al. (1999) \\
Eukaryotic RNase P & 143 & Tekos et al. (2000) \\
RNA-protein complexes & & \\
RRE-rev & 1 & Zapp et al. (1993) \\
TAR-tat & 1 & Mei et al. (1997) \\
Enzymes & & \\
Phospholipase C & & McDonald and Mamrack (1995) \\
DNase I & $3-10$ & Woegerbauer et al. (2000) \\
DNA pol I & $\sim 1 \times 10^{3}$ & Lazarus and Kitron (1973) \\
Phenylalanylation of tRNA & $\sim 5 \times 10^{2}$ & Mikkelsen et al. (2001) \\
\hline
\end{tabular}

\footnotetext{
${ }^{\text {a }}$ The given neomycin $\mathrm{B}$ values correspond to determined $K_{i}$ values for the listed ribozymes.

${ }^{b}$ The given neomycin $B$ values correspond to the concentrations of neomycin $B$ that abolish RNA-protein complex formation.

${ }^{\mathrm{c}}$ The given neomycin $\mathrm{B}$ values correspond to the concentrations of neomycin $\mathrm{B}$ that inhibit the enzymatic activity.

${ }^{d}$ Inhibition of phenylalanyl-tRNA-synthetase is caused by neomycin B binding the tRNA substrate (Mikkelsen et al., 2001). It has been shown that tobramycin inhibits tRNA aminoacylation by binding and inducing a conformational change in tRNA (Walter et al., 2002).
} 
using Lineweaver-Burk formalism (Fig. 3A-C). In all cases, the results were compatible with a mixed noncompetitive mechanism of inhibition, indicating that the neomycin B-binding sites do not completely overlap with the binding sites for the substrates. We also investigated if single- or double-stranded DNA of sizes similar to those of the DNA template could release the inhibitory effect of neomycin B on Klenow pol and found no evidence for this (data not shown). These results are not compatible with a model of inhibition based on neomycin B binding to any of the substrates, making them inappropriate as substrates for the enzymes. To determine the $K_{i}$ values kinetically we replotted the slopes of the lines in Figure 3 as a function of neomycin B concentration (see insets, Fig. 3). From this analysis, the $K_{i}$ values for neomycin $\mathrm{B}$ were determined to be $0.4 \mu \mathrm{M}$ for PARN and $2.8 \mathrm{mM}$ titrating the DNA template or $3.1 \mathrm{mM}$ titrating the dCTP substrate for Klenow pol, in keeping with the ${ }_{\text {app }} K_{i}$ values listed in Table 1.

\section{Inhibition by aminoglycosides is released by addition of $\mathbf{M g}$ (II) ions}

The data presented so far is in agreement with a model of inhibition where aminoglycosides and divalent metal
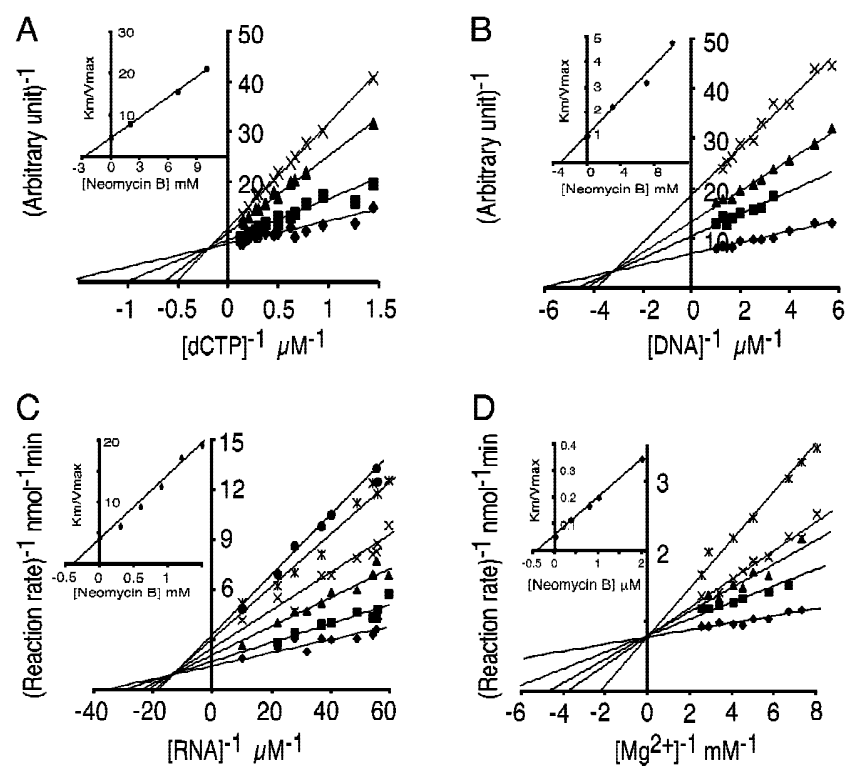

FIGURE 3. Kinetic analysis of inhibition. A, B, C: Neomycin B is a mixed noncompetitive inhibitor. Double reciprocal plots $1 / v$ versus $1 /$ [substrate] of indicated substrate for Klenow pol (A and $\mathbf{B})$ and PARN (C) activities in the presence of neomycin $B$ are shown. The neomycin B concentrations were: A: $(\diamond) 0 \mathrm{mM},(\boldsymbol{\square}) 2 \mathrm{mM},(\boldsymbol{\Delta}) 7 \mathrm{mM}$, and $(\times) 10 \mathrm{mM}$; B: (४) $0 \mathrm{mM},(\boldsymbol{\square}) 3 \mathrm{mM},(\boldsymbol{\Delta}) 7 \mathrm{mM}$, and $(\times) 10 \mathrm{mM}$; C: $(\diamond) 0 \mu \mathrm{M},(\boldsymbol{\square}) 0.3 \mu \mathrm{M},(\boldsymbol{\Delta}) 0.6 \mu \mathrm{M},(\times) 0.9 \mu \mathrm{M},(*) 1.2 \mu \mathrm{M}$, and $(\bullet)$ $1.5 \mu \mathrm{M}$. Insets: The slopes $\left(K_{m} / V_{\max }\right)$ of the double reciprocal lines versus the neomycin B concentrations. D: Inhibition of PARN activity by neomycin $\mathrm{B}$ is released in a competitive manner by $\mathrm{Mg}$ (II) ions. Double reciprocal plots, $1 / \mathrm{v}$ versus $1 /\left[\mathrm{Mg}^{2+}\right]$ for PARN activity in the presence of neomycin $\mathrm{B}(\diamond) 0 \mu \mathrm{M},(\boldsymbol{\square}) 0.36 \mu \mathrm{M},(\boldsymbol{\Delta}) 0.8 \mu \mathrm{M},(\times)$ $1 \mu \mathrm{M}$, and (*) $2 \mu \mathrm{M}$, are shown. Inset: The slopes $\left(K_{m} / V_{\max }\right)$ of the double reciprocal lines versus the neomycin $B$ concentrations. ions compete for overlapping binding sites. This model predicts that an increase in divalent metal ions should release the aminoglycoside inhibition in a competitive manner. To investigate this, we performed deadenylation reactions at various concentrations of neomycin $B$ $(0.36,0.8,1$, or $2 \mu \mathrm{M})$. To these reactions, increasing amounts of $\mathrm{Mg}$ (II) ions (from 0.1 to $0.4 \mathrm{mM}$ ) were added. Figure 3D shows that addition of $\mathrm{Mg}(\mathrm{II})$ ions released the aminoglycoside inhibition in a competitive manner, that is, only the $K_{M}$ parameter and not the $V_{\max }$ value was affected. From these plots we also determined the $K_{i}$ value to $0.4 \mu \mathrm{M}$, similar to the estimated ${ }_{\text {app }} K_{i}$ (Table 1) and kinetically determined $K_{i}$ (Fig. $\left.3 \mathrm{~A}-\mathrm{C}\right)$ values, suggesting that the $K_{i}$ value of neomycin B for PARN is independent of the concentration of $\mathrm{Mg}$ (II) ions. We also found, in analogy with PARN, that the inhibition of Klenow pol was released by increasing the concentration of either $\mathrm{Mg}$ (II) or $\mathrm{Mn}$ (II) ions (data not shown). In conclusion, these data suggest that neomycin B and divalent metal ions compete for the same or at least overlapping binding sites.

\section{Aminoglycosides perturb iron-mediated cleavage in the active sites of Klenow pol and PARN}

The active site for polymerization of Klenow pol has been defined functionally by mutagenesis and structurally by crystallographic studies (reviewed in Joyce \& Steitz, 1995; Brautigam \& Steitz, 1998; Steitz, 1999) whereas the active site of PARN has been identified by site-directed mutagenesis (Ren et al., 2002). A twometal-ion mechanism for polymerization has been suggested for Klenow pol and the crystal structure reveals acidic amino acid residues involved in coordinating essential divalent metal ions at the polymerase active site (Brautigam \& Steitz, 1998). The active site of PARN resembles the $3^{\prime}$ exonuclease active site of Klenow pol, and the key acidic amino acid residues involved in the coordination of divalent metal ions are structurally conserved between the two sites (Korner et al., 1998; Ren et al., 2002).

To visualize the divalent ions located in the active sites of Klenow pol and PARN experimentally, we performed iron-mediated hydroxyl radical cleavages of the corresponding polypeptides (Fig. 4). Prominent cleavage products, being approximately $50 \mathrm{kDa}$ for Klenow pol and 35 and $48 \mathrm{kDa}$ in sizes for PARN, accumulated over time (Fig. 4B, lanes 10-12). It has been established that the accumulation of the iron-mediated cleavage products of PARN requires the conserved acidic residues in the active site, suggesting that the iron(II) binding sites are located in the vicinity of the PARN active site (Ren et al., 2002). To identify amino acids important for the iron-mediated cleavage of the Klenow pol fragment, we mutated individually each acidic amino acid, involved in coordinating the divalent metal ions of 


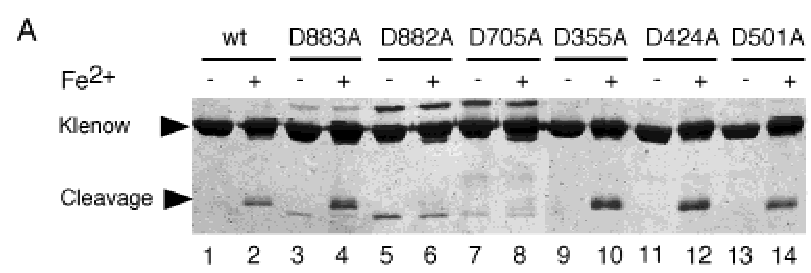

B
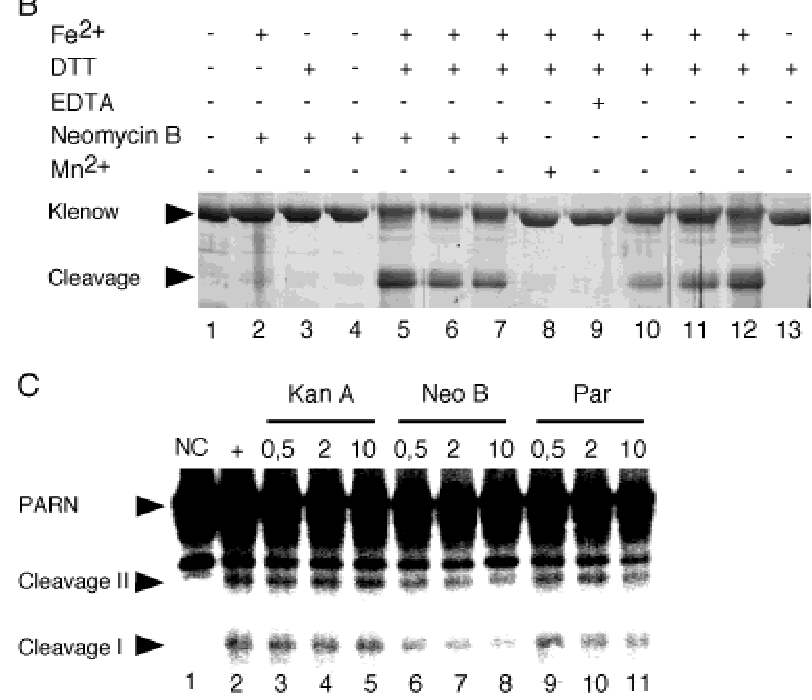

FIGURE 4. Aminoglycosides perturb Fe (II)-mediated cleavages of Klenow pol and PARN. A: The acidic amino acid residues D705 and D882 in the active site of the polymerase domain of Klenow pol are required for $\mathrm{Fe}$ (II) mediated cleavage. Indicated Klenow pol polypeptide was subjected to $\mathrm{Fe}$ (II)-mediated cleavage as outlined in Materials and Methods. The resulting fluorogram is shown. Presence $(+)$ or absence $(-)$ of $20 \mu \mathrm{M} \mathrm{Fe}$ (II) in the cleavage reactions are indicated. The location of Klenow pol and cleavage product is indicated. The polypeptide band migrating slightly faster than the cleavage product is a contaminating polypeptide already present in some of our preparations before Fe(II)-mediated cleavage. B: Fe (II)mediated cleavage reactions of Klenow pol were performed as described in Materials and Methods in the absence $(-)$ or presence $(+)$ of indicated reagent, EDTA (lane 9, $50 \mu \mathrm{M}$ ), $\mathrm{Mn}^{2+}$ (lane 8, $10 \mathrm{mM}$ ), or Neomycin B (lanes 2-4, 1,000 $\mu \mathrm{M}$; lane 5, $10 \mu \mathrm{M}$, lane 6, $100 \mu \mathrm{M}$, and lane 7, 1,000 $\mu \mathrm{M}$ ). The incubation times were 5, 10, and $20 \mathrm{~min}$ in lanes 10, 11, and 12, respectively. C: Fe (II)-mediated cleavage reactions of $\left[{ }^{32} \mathrm{P}\right]$-labeled recombinant PARN polypeptides were performed in the presence of neomycin $B(N e o B)$, paromomycin (Par), or kanamycin A (Kan A) as outlined in Materials and Methods. The resulting fluorogram is shown. The concentrations of the aminoglycosides were $0.5 \mu \mathrm{M}$ (lanes 3, 6, and 9), $2 \mu \mathrm{M}$ (lanes 4, 7, and 10) and $10 \mu \mathrm{M}$ (lanes 5, 8, and 10). In lane 1 (NC) PARN was incubated in the absence of aminoglycoside, $\mathrm{Fe}^{2+}$, and DTT. In lane $2(+)$ PARN was incubated in the absence of added aminoglycoside but in the presence of $\mathrm{Fe}^{2+}$ and DTT.

the polymerase and exonuclease active sites, to alanine residues. Subsequently, each mutated Klenow pol fragment was subjected to iron-mediated hydroxyl radical cleavage. Figure $4 \mathrm{~A}$ shows that amino acids Asp(705) and Glu(882) located in the active site of polymerization were crucial for generating the $50-\mathrm{kDa}$ cleavage product, suggesting that the iron ions that generate the $50-\mathrm{kDa}$ cleavage product are coordinated at this site of Klenow pol. Finally, we found that the iron-mediated cleavage of Klenow pol fragment was dependent on the presence of $\mathrm{Fe}$ (II) ions (Fig. 4B, lanes 10-13) and was abolished by the addition of $\mathrm{Mn}$ (II) (Fig. 4B) or Mg(II) (data not shown) ions, suggesting that the $\mathrm{Fe}(\mathrm{II})$ ions' binding sites overlapped with the $\mathrm{Mn}$ (II) or $\mathrm{Mg}$ (II) ions' binding sites.

An important prediction from our aminoglycoside inhibition results (Table 1; Figs. 2 and 3 ) is that the addition of aminoglycosides should bind and displace the iron ions in the active sites and thereby attenuate the iron-mediated cleavages. To test this, we added increasing amount of aminoglycosides and investigated if this perturbed iron-mediated cleavage. Figure 4B, lanes $5-7$, shows that the accumulation of the Klenow pol 50-kDa cleavage product was inhibited by the addition of an increasing amount of neomycin $B$. In the case of PARN, an increase in the concentration of neomycin $B$ reduced iron-mediated cleavage at both cleavage sites (Fig. 4C, lanes 6-8). In contrast, kanamycin A, a poor inhibitor of PARN, did not significantly affect the iron-mediated cleavage whereas paromomycin, which is an intermediary inhibitor of PARN, reduced iron-mediated cleavage moderately (Fig. 4C, lanes 3-5 and 9-11). In conclusion, our data show that aminoglycosides attenuate iron-mediated cleavage in the active sites of both enzymes. These results are in agreement with a model of inhibition in which aminoglycosides displace functionally important divalent metal ions in the active sites of both enzymes.

\section{DISCUSSION}

\section{Mechanism of inhibition}

In this report, we demonstrate that aminoglycosides inhibit the catalytic activity of two metalloenzymes, Klenow pol and PARN. We propose that the aminoglycoside binds the enzymes in the vicinity of their active sites and thereby inhibits their catalytic activities. In analogy with the inhibition of ribozyme activity by aminoglycosides (see Rogers et al., 1996; Hermann \& Westhof, 1998; Hoch et al., 1998; Walter et al., 1999; Mikkelsen et al., 1999, 2001, and references therein) we suggest that the inhibition is caused by the aminoglycoside distorting the active site and/or displacing functionally important divalent metal ions. The kinetic data showing that neomycin $B$ is a mixed noncompetitive inhibitor of both enzymes (Fig. 3 ) is compatible with this model of inhibition. Further support is provided by the observation that neomycin $B$ perturbed the iron-mediated hydroxyl radical cleavage reactions in the vicinity of the active sites of both enzymes (Fig. 4). Finally, the kinetic evidence that the neomycin B inhibition of PARN was released in a competitive manner by $\mathrm{Mg}$ (II) ions (Fig. 3 ) is in direct line with this proposal.

It has previously been suggested that neomycin B inhibits DNA polymerase I (Lazarus \& Kitron, 1973) and DNase I of E. coli (Woegerbauer et al., 2000) by binding to the DNA substrates. However, our results provide no 
evidence for this mechanism of inhibition, neither for Klenow pol nor PARN. Most importantly, our kinetic analysis (Fig. 3) revealed that neomycin B was a mixed noncompetitive inhibitor of both Klenow pol and PARN. In these analyses, neomycin B should not have affected the $V_{\max }$ parameters if inhibition was due to neomycin $\mathrm{B}$ being complexed with any of the substrates. We also found, in the case of Klenow pol, that addition of large amounts of nonsubstrate nucleic acids (i.e., singlestranded DNA or double-stranded DNA with blunt or $5^{\prime}$ protruding ends) did not release the inhibition. Finally, we found that the $K_{i}$ values for both enzymes were independent of the substrate concentrations (Fig. 3). The large excess of $\mathrm{Mg}$ (II) ions compared to the amount of aminoglycoside required to inhibit PARN (e.g., the $\mathrm{Mg}$ (II) ion concentration was more than 1,000-fold higher than the $K_{i}$ value for neomycin B) argues that the chelating properties of aminoglycosides were not causing the inhibition.

Taken together we favor a model of inhibition where the aminoglycoside binds the active site of the enzyme and thereby interferes with its function. Furthermore, it is plausible that the aminoglycoside binding site overlaps with the binding sites for essential divalent metal ions and that aminoglycoside binding displaces functionally important metal ions. This model of inhibition resembles models for inhibition of ribozyme activities by aminoglycosides (see Hermann \& Westhof, 1998; Hoch et al., 1998; Mikkelsen et al., 1999, 2001, and references therein) and is analogous to how the amino group of 2'-O-aminopropyl substituted RNA directly interferes with divalent metal ion binding at the exonuclease active site of Klenow pol (Teplova et al., 1999).

\section{Aminoglycosides and toxicity}

Aminoglycosides are among the most potent and best known antibiotics. However, they are not used against bacterial infections as frequently as they used to be due to a variety of severe side effects (reviewed in Zembower et al., 1998). The mechanisms behind toxicity are not understood and several potential causes have been discussed in the literature, for example, inhibition of phospholipase C (McDonald \& Mamrack, 1995), increased formation of free radicals (Schacht, 1999), and inhibition of protein synthesis or other essential ribozyme activities (see Walter et al., 1999, and references therein). The observations that aminoglycosides inhibit Klenow pol and PARN suggest that inhibition of nucleic acid metabolizing enzymes may be a common mechanism by which aminoglycosides cause unwanted side effects. In support of this, we have preliminary evidence that several other nucleic acid metabolizing enzymes, among them BamHI restriction enzyme, HIV reverse transcriptase, bacterial RNase $\mathrm{H}$, Taq DNA polymerase, and T7 RNA polymerase, can be inhibited in vitro by neomycin B (our unpubl. observations). It is interesting to note that phospholipase $\mathrm{C}$ is, as are Klenow pol and PARN, a metalloenzyme that breaks phosphodiester bonds (Hansen et al., 1993). This implies that binding to and inhibition of metalloenzymes involved in breaking and forming phosphodiester bonds may be a general feature of aminoglycosides that lies behind many of the different toxic side effects caused by aminoglycosides.

\section{Aminoglycosides as "metal mimics"}

We have recently suggested that aminoglycosides can be considered as "metal mimics" (Mikkelsen et al., 2001), because they bind to metal-ion binding sites of RNA molecules and interfere with the function of RNA by displacing functionally/structurally important $\mathrm{Me}$ (II) ions. In this study, we show that aminoglycosides also interfere with metal-ion binding sites of protein enzymes, showing that the "metal mimics" property of aminoglycosides is not only restricted to the interaction between aminoglycosides and RNA. Thus, aminoglycosides as "metal mimics" have the potential to be used as functional probes to perturb the catalytic activity of both ribozymes and metalloenzymes, and, as functional/ structural probes, to map and characterize the active sites of such catalytic activities. The experiments shown in Figure 4 combined with experiments designed to identify amino acids in the active site by site-directed mutagenesis and map divalent metal-ion binding sites by iron-induced hydroxl radical cleavage (as exemplified in Ren et al., 2002) provide a working platform for how aminoglycosides can be used to functionally/ structurally probe the active site of such catalytic activities. Finally we note that aminoglycosides as "metal mimics" can serve as starting compounds for development of novel drugs (e.g., antibiotics) and that aminoglycosides or derivatives thereof can be used as ligands to identify metal-binding proteins in systematic screening efforts using the protein microarray technique recently developed by MacBeath and Schreiber (2000).

\section{MATERIALS AND METHODS}

\section{Molecular cloning and expression}

A DNA fragment encoding Klenow DNA polymerase was obtained by PCR amplification using $E$. coligenomic DNA (strain MG1655) as template and oligonucleotides 5' -TACATATGA TTTCTTATGACAACTACGTC-3' and 5'-TGCGGATCCTAG TGCGCCTGATCCCA-3' as the primers. The obtained DNA fragment was cloned into the pCR 2.1TOPO vector (Invitrogen) and then subcloned into the pET-19 vector (Novagen Inc.) between the Ndel and BamHI sites. The obtained plasmid was named pKI. Plasmid pKI was subsequently subjected to site-specific mutagenesis using the QuickChange Site-Directed Mutagenesis Kit (Stratagene) following the instructions from the supplier. The sequences of the resulting mutants [i.e., pKI(D355A, E357A), pKI(D355A, E357A, D424A), pKI(D355A, E357A, D424A), pKI(D355A, E357A, D501A), 
pKI(D355A, E357A, D705A), pKI(D355A, E357A, E883A), and pKI(D355A, E357A, D882A)] were verified by DNA sequence analysis. The following primer pairs were used for generation of site-directed mutants:

KI(D355A, E357A): 5'-CGGTATTTGCATTTGCCACCGCAA CCGACAGCCTTG-3' and 5'-CAAGGCTGTCGGTTGCG GTGGCAAATGCAAATACCG-3';

KI(D424A): 5'-CCAGAATACCGCGTGCGTATTTCAGGTTT TG-3' and 5'-CAAAACCTGAAATACGCACGCGGTATTC GG-3';

KI(D501A): 5'-GTTACGCCGCCGAAGCAGCAGATGTCAC CTTG-3' and 5'-GGTGACATCTGCTGCTTCGGCGGC GT-3';

KI(D705A): 5'-GTGATTGTCTCAGCGGCCTACTCGCAG ATTG-3' and 5'-GGTGACATCTGCTGCTTCGGCGGC GT-3';

KI(E883A): 5'-GATCATGCAGGTACACGATGCACTGGTAT TTGAAGTTC-3' and GAACTTCAAATACCAGTGCATCG TGTACCTGCATGATC-3';

KI(D882A): 5'-GATCATGCAGGTACACGCCGAACTGGTAT TTGAAGTTC-3' and 5'-GAACTTCAAATACCAGTTCGG CGTGTACCTGCATGATC-3'.

His-tagged Klenow fragment and mutant polypeptides were expressed in E. coli strain BL21(DE3)pLysS. The extracted recombinant polypeptides were purified by metal affinity chromatography using the TALON (Clontech Inc.) or Ni- (Novagen Inc.) matrices as outlined by the manufacturers. The amount of protein was measured with a BioRad protein assay kit and the purity was determined by SDS-polyacrylamide gel electrophoresis followed by silver staining.

\section{Assay and quantification of Klenow and PARN activities}

To test for Klenow polymerase activity, we used the Klenow(D355A,E357A) recombinant polypeptide, in which the 3'-5' exonuclease active site was inactivated by site-directed mutagenesis, as the enzyme and a double-stranded DNA fragment, generated by hybridization of oligonucleotides $5^{\prime}$ TCGCAGCCGTGAG-3' and 5'-ATCCAAGCTCACGGCTG CGA-3', as the template. The DNA template was prepared as described (Eger \& Benkovic, 1992). The reactions were performed in $10 \mu \mathrm{L}$ in the presence of $100 \mathrm{mM}$ HEPES-KOH, $\mathrm{pH}$ 7.0, $1 \mathrm{mM}$ DTT, $0.5 \mu \mathrm{g} / \mu \mathrm{L}$ BSA, $150 \mathrm{mM} \mathrm{KCl}, 4 \mathrm{mM}$ $\mathrm{MgCl}_{2}, 10 \mathrm{mM}$ spermidine, $1 \mu \mathrm{M}$ DNA template, $0.3 \mu \mathrm{M}(\alpha-$ $\left.{ }^{32} \mathrm{P}\right) \mathrm{dCTP}$ (3,000 Ci/mmol; Amersham Pharmacia Biotech) and contained $0.2-1 \mathrm{nM}$ of indicated Klenow pol fragment. Reactions were incubated at $30^{\circ} \mathrm{C}$ for $5-20 \mathrm{~min}$ and then stopped by the addition of $10 \mu \mathrm{L}$ loading buffer (80\% formamide (v/v), 0.1\% xylene cyanol, $0.1 \%$ bromophenol blue, $50 \mathrm{mM}$ Tris- $\mathrm{HCl}, \mathrm{pH} 7.9,50 \mathrm{mM}$ EDTA). The reacted DNA was fractionated by $10 \%$ polyacrylamide (19:1 acrylamide/ bisacrylamide 30:0.8 )-7 M urea gel electrophoresis. The resulting gel was scanned using a $400 \mathrm{~S}$ Phosphorlmager (Molecular Dynamics). When dCTP was titrated, the DNA template concentration was $1 \mu \mathrm{M}$, whereas the dCTP concentration was $50 \mu \mathrm{M}$ when the DNA template was titrated. The $\mathrm{pH}$ of the reactions was 7.0 if not stated otherwise. The consumption of substrate (dCTP or DNA) was controlled so that not more than $20 \%$ of its total amount was consumed.
Homogeneously purified calf thymus PARN 54-kDa active fragment was used as the source of PARN (Martinez et al., 2000). Recombinant full-length human PARN was expressed and purified as described (Martinez et al., 2000). As substrate, we used $L 3\left(A_{30}\right)$ RNA radioactively labeled with ${ }^{32} \mathrm{P}$ in its poly (A) tail (Åström et al., 1991). Assay conditions and 1-D TLC quantitation procedures were as previously described (Åström et al., 1992). The $\mathrm{pH}$ of the deadenylation reactions were 7.0, unless stated otherwise. The consumption of $L 3\left(A_{30}\right)$ RNA substrate was controlled so that no more than $20 \%$ of it was consumed.

Aminoglycosides were purchased from Sigma Chemical Co. and added amount was as indicated. The polymerization and deadenylation efficiencies were plotted as a function of the concentration of the aminoglycoside under study. The app $K_{i}$ was defined as the concentration of added aminoglycoside resulting in $50 \%$ inhibition of Klenow pol or PARN activities. $K_{i}$ values were obtained by plotting the determined $-\left(K_{M} / V_{\max }\right)$ values against the concentration of aminoglycoside under study.

\section{$\mathrm{Fe}(\mathrm{II})$-mediated hydroxyl radical cleavage}

Two to four micrograms of purified recombinant Klenow pol fragment or mutant thereof, dialyzed against buffer $F(20 \mathrm{mM}$ HEPES-KOH, pH 7.0, $5 \mathrm{mM} \mathrm{NaCl}$ ) on a Milipore "V" Series Membrane (Millipore) for $30 \mathrm{~min}$ at $4{ }^{\circ} \mathrm{C}$, were incubated for $20 \mathrm{~min}$ at $37^{\circ} \mathrm{C}$ in $50 \mathrm{mM}$ HEPES, pH 7.0, $5 \mathrm{mM} \mathrm{NaCl}, 20 \mu \mathrm{M}$ $\mathrm{Fe}\left(\mathrm{NH}_{4}\right)_{2} \mathrm{SO}_{4}$ and $10 \mathrm{mM}$ DTT in a total volume of $10 \mu \mathrm{L}$. The incubations were stopped by the addition of $10 \mu \mathrm{L}$ of $2 \times$ SDS-loading buffer (100 mM Tris-HCl, pH 6.8, 2\% (w/v) SDS, $200 \mathrm{mM}$ DTT, 16\% (v/v) glycerol, 0.05\% (w/v) bromophenol blue, and $50 \mathrm{mM}$ EDTA). The amount of added Mg(II)-ions, $\mathrm{Mn}$ (II)-ions, or aminoglycoside was as indicated. Reacted polypeptides were fractionated by $10 \%$ SDS-polyacrylamide gel electrophoresis and subsequently visualized by silver staining.

Recombinant PARN polypeptides expressed in E. coli were purified and radioactively labeled with ${ }^{32} \mathrm{P}$ in their $\mathrm{N}$ termini as described (Ren et al., 2002). Fe(II)-mediated hydroxyl radical cleavage of PARN was performed as previously described (Ren et al., 2002). Reacted samples were subjected to $10 \%$ SDS-polyacrylamide gel electrophoresis and the resulting gel was subsequently visualized and quantified using a 400 S Phosphorlmager (Molecular Dynamics). In the Mg(II) and $\mathrm{Mn}(\mathrm{II})$ ions competition experiments, $\mathrm{MgCl}_{2}$ or $\mathrm{MnCl}_{2}$ was added at indicated concentration in the presence of $20 \mu \mathrm{M}$ $\mathrm{Fe}\left(\mathrm{NH}_{4}\right)_{2} \mathrm{SO}_{4}$.

\section{ACKNOWLEDGMENTS}

We thank N. Balatsos, M. Ehrenberg, N. Henriksson, C. Kyriakopoulou, P. Nilsson, H. Nordvarg, and A-C. Thuresson for valuable suggestions, comments on the manuscript, and discussions throughout the completion of this work. Dr. R. Schroeder is acknowledged for helpful comments and for convincing us to initiate this investigation. We are grateful to Dr. E. Westhof for fruitful discussions and comments on the manuscript. This work was supported by the Swedish Strategic Research Foundation and funds at Uppsala University.

Received July 1, 2002; returned for revision July 12, 2002; revised manuscript received August 6, 2002 


\section{REFERENCES}

Åström J, Åström A, Virtanen A. 1991. In vitro deadenylation of mammalian mRNA by a HeLa cell 3' exonuclease. EMBO J 10:30673071.

Åström J, Åström A, Virtanen A. 1992. Properties of a HeLa cell 3' exonuclease specific for degrading poly $(A)$ tails of mammalian mRNA. J Biol Chem 267:18154-18159.

Botto RE, Coxon B. 1983. Nitrogen-15 nuclear magnetic resonance spectroscopy of neomycin $\mathrm{B}$ and related aminoglycosides. J Am Chem Soc 105:1021-1028.

Brautigam CA, Steitz TA. 1998. Structural and functional insights provided by crystal structures of DNA polymerases and their substrate complexes. Curr Opin Struc Biol 8:54-63.

Brodersen DE, Clemons WM Jr, Carter AP, Morgan-Warren RJ, Wimberly BT, Ramakrishnan V. 2000. The structural basis for the action of the antibiotics tetracycline, pactamycin, and hygromycin B on the 30S ribosomal subunit. Cell 103:1143-1154.

Carter AP, Clemons WM, Brodersen DE, Morgan-Warren RJ, Wimberly BT, Ramakrishnan V. 2000. Functional insights from the structure of the $30 \mathrm{~S}$ ribosomal subunit and its interactions with antibiotics. Nature 407:340-348.

Copeland PR, Wormington M. 2001. The mechanism and regulation of deadenylation: Identification and characterization of Xenopus PARN. RNA 7:875-886.

Davies J. 1994. New pathogens and old resistance genes. Microbiologia 10:9-12.

Davies J, Wright GD. 1997. Bacterial resistance to aminoglycoside antibiotics. Trends Microbiol 5:234-240.

Earnshaw DJ, Gait MJ. 1998. Hairpin ribozyme cleavage catalyzed by aminoglycoside antibiotics and the polyamine spermine in the absence of metal ions. Nucleic Acids Res 26:5551-5561.

Eger BT, Benkovic SJ. 1992. Minimal kinetic mechanism for misincorporation by DNA polymerase I (Klenow fragment). Biochemistry 31:9227-9236.

Fourmy D, Recht MI, Blanchard SC, Puglisi JD. 1996. Structure of the A site of Escherichia coli 16S ribosomal RNA complexed with an aminoglycoside antibiotic. Science 274:1367-1371.

Fourmy D, Yoshizawa S, Puglisi JD. 1998. Paromomycin binding induces a local conformational change in the A-site of $16 \mathrm{~S}$ rRNA. J Mol Biol 277:333-345.

Hansen S, Hansen LK, Hough E. 1993. The crystal structure of trisinhibited phospholipase $\mathrm{C}$ from Bacillus cereus at $1.9 \mathrm{~A}$ resolution. The nature of the metal ion in site 2. J Mol Biol 231:870-876.

Hermann T, Westhof E. 1998. Aminoglycoside binding to the hammerhead ribozyme: A general model for the interaction of cationic antibiotics with RNA. J Mol Biol 276:903-912.

Hoch I, Berens C, Westhof E, Schroeder R. 1998. Antibiotic inhibition of RNA catalysis: Neomycin B binds to the catalytic core of the td group I intron displacing essential metal ions. J Mol Biol 282:557569.

Joyce CM, Steitz TA. 1995. Polymerase structures and function: Variations on a theme? J Bacteriol 177:6321-6329.

Korner CG, Wahle E. 1997. Poly (A) tail shortening by a mammalian poly(A)-specific 3'-exoribonuclease. J Biol Chem 272:1044810456.

Korner CG, Wormington M, Muckenthaler M, Schneider S, Dehlin E, Wahle E. 1998. The deadenylating nuclease (DAN) is involved in poly $(\mathrm{A})$ tail removal during the meiotic maturation of Xenopus oocytes. EMBO J 17:5427-5437.

Lazarus LH, Kitron N. 1973. Neomycin inhibition of DNA polymerase. Biochem Pharmacol 22:3115-3117.

MacBeath G, Schreiber SL. 2000. Printing proteins as microarrays for high-throughput function determination. Science 289:17601763.

Martinez J, Ren YG, Thuresson AC, Hellman U, Astrom J, Virtanen A. 2000. A 54-kDa fragment of the poly (A)-specific ribonuclease is an oligomeric, processive, and cap-interacting poly (A)-specific 3' exonuclease. J Biol Chem 275:24222-24230.

McDonald LJ, Mamrack MD. 1995. Phosphoinositide hydrolysis by phospholipase $\mathrm{C}$ modulated by multivalent cations $\mathrm{La}(3+), \mathrm{Al}(3+)$, neomycin, polyamines, and melittin. $J$ Lipid Mediat Cell Signal 11:81-91.

Mei HY, Mack DP, Galan AA, Halim NS, Heldsinger A, Loo JA, Moreland DW, Sannes-Lowery KA, Sharmeen L, Truong HN,
Czarnik AW. 1997. Discovery of selective, small-molecule inhibitors of RNA complexes-I. The Tat protein/TAR RNA complexes required for HIV-1 transcription. Bioorg Med Chem 5:1173-1184.

Mian IS. 1997. Comparative sequence analysis of ribonucleases HII, III, II PH and D. Nucleic Acids Res 25:3187-3195.

Mikkelsen NE, Brännvall M, Virtanen A, Kirsebom L. 1999. Inhibition of RNase P cleavage by aminoglycosides. Proc Natl Acad Sci USA 96:6155-6160.

Mikkelsen NE, Johansson K, Virtanen A, Kirsebom LA. 2001. Aminoglycoside binding displaces a divalent metal ion in a tRNAneomycin B complex. Nat Struct Biol 8:510-514.

Moazed D, Noller HF. 1987. Interaction of antibiotics with functional sites in 16S ribosomal RNA. Nature 327:389-394.

Ren YG, Martinez J, Virtanen A. 2002. Identification of the active site of poly (A)-specific ribonuclease by site-directed mutagenesis and $\mathrm{Fe}(2+)$-mediated cleavage. J Biol Chem 277:5982-5987.

Rogers J, Chang AH, von Ahsen U, Schroeder R, Davies J. 1996. Inhibition of the self-cleavage reaction of the human hepatitis delta virus ribozyme by antibiotics. J Mol Biol 259:916-925.

Schacht J. 1999. Antioxidant therapy attenuates aminoglycosideinduced hearing loss. Ann NY Acad Sci 884:125-130.

Stage TK, Hertel KJ, Uhlenbeck OC. 1995. Inhibition of the hammerhead ribozyme by neomycin. RNA 1:95-101.

Steitz TA. 1999. DNA polymerases: Structural diversity and common mechanisms. J Biol Chem 274:17395-17398.

Steitz TA, Steitz JA. 1993. A general two-site-metal-ion mechanism for catalytic RNA. Proc Natl Acad Sci USA 90:6498-6502.

Szilagyi L, Pusztahelyi ZS, Jakab S, Kovacs I. 1993. Microscopic protonation constants in tobramycin. An NMR and pH study with the aid of partially N-acetylated derivatives. Carbohydr Res 247: 99-109.

Tekos A, Tsagla A, Stathopoulos C, Drainas D. 2000. Inhibition of eukaryotic ribonuclease $\mathrm{P}$ activity by aminoglycosides: Kinetic studies. FEBS Lett 485:71-75.

Teplova M, Wallace ST, Tereshko V, Minasov G, Symons AM, Cook PD, Manoharan M, Egli M. 1999. Structural origins of the exonuclease resistance of a zwitterionic RNA. Proc Natl Acad Sci USA 96:14240-14245.

Tor Y, Hermann T, Westhof E. 1998. Deciphering RNA recognition: Aminoglycoside binding to the hammerhead ribozyme. Chem Biol 5:277-283.

Vicens Q, Westhof E. 2001. Crystal structure of paromomycin docked into the eubacterial ribosomal decoding A site. Structure (Camb) 9:647-658.

von Ahsen U, Davies J, Schroeder R. 1991. Antibiotic inhibition of group I ribozyme function. Nature 353:368-370.

von Ahsen U, Davies J, Schroeder R. 1992. Non-competitive inhibition of group I intron RNA self-splicing by aminoglycoside antibiotics. J Mol Biol 226:935-941.

Walter F, Putz J, Giege R, Westhof E. 2002. Binding of tobramycin leads to conformational changes in yeast tRNA(Asp) and inhibition of aminoacylation. EMBO J 21:760-768.

Walter F, Vicens Q, Westhof E. 1999. Aminoglycoside-RNA interactions. Curr Opin Chem Biol 3:694-704.

Wang H, Tor Y. 1997. Electrostatic interactions in RNA aminoglycosides binding. J Am Chem Soc 119:8734-8735.

Werstuck G, Zapp ML, Green MR. 1996. A non-canonical base pair within the human immunodeficiency virus rev-responsive element is involved in both rev and small molecule recognition. Chem Biol 3:129-137.

Woegerbauer M, Burgmann H, Davies J, Graninger W. 2000. DNase I induced DNA degradation is inhibited by neomycin. J Antibiot (Tokyo) 53:276-285.

Woodcock J, Moazed D, Cannon M, Davies J, Noller HF. 1991. Interaction of antibiotics with A- and P-site-specific bases in 16S ribosomal RNA. EMBO J 10:3099-3103.

Yoshizawa S, Fourmy D, Puglisi JD. 1998. Structural origins of gentamicin antibiotic action. EMBO J 17:6437-6448.

Zapp ML, Stern S, Green MR. 1993. Small molecules that selectively block RNA binding of HIV-1 Rev protein inhibit Rev function and viral production. Cell 74:969-978.

Zembower TR, Noskin GA, Postelnick MJ, Nguyen C, Peterson LR. 1998. The utility of aminoglycosides in an era of emerging drug resistance. Int J Antimicrob Agents 10:95-105. 

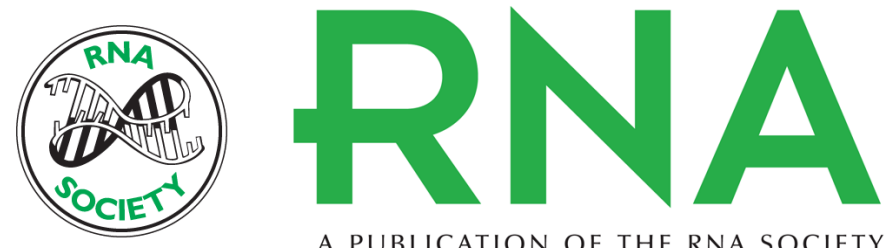

A PUBLICATION OF THE RNA SOCIETY

\section{Inhibition of Klenow DNA polymerase and poly(A)-specific ribonuclease by aminoglycosides.}

Yan-Guo Ren, Javier Martínez, Leif A Kirsebom, et al.

RNA 2002 8: 1393-1400

\section{License}

Email Alerting Receive free email alerts when new articles cite this article - sign up in the box at the Service top right corner of the article or click here. 